\title{
Use of laser technology to produce high thermoelectric performances in
}

$\mathrm{Bi}_{2} \mathrm{Sr}_{2} \mathrm{Co}_{1.8} \mathrm{O}_{\mathrm{x}}$

Sh. Rasekh ${ }^{1}$, F. M. Costa ${ }^{2}$, N. M. Ferreira ${ }^{2}$, M. A. Torres ${ }^{1}$, M. A. Madre ${ }^{1}$, J. C. Diez $^{1}$, A. Sotelo ${ }^{1}$

${ }^{1}$ ICMA (CSIC-Universidad de Zaragoza), C/María de Luna 3, 50018-Zaragoza (Spain).

${ }^{2}$ i3N, Departamento de Física, Universidade de Aveiro, 3810-193 Aveiro, Portugal.

\section{Abstract}

Intrinsically nanostructured $\mathrm{Bi}_{2} \mathrm{Sr}_{2} \mathrm{Co}_{1.7} \mathrm{O}_{\mathrm{x}}$ bulk polycrystalline ceramics were prepared by a polymer solution method and by directional growth. Moreover, the effect of annealing on the as-grown materials has been studied.

Microstructure has shown randomly oriented grains in the classical sintered materials while in the textured samples they were well oriented with their c-axis nearly perpendicular to the growth direction. Furthermore, the annealed samples showed much lower amount of secondary phases than the as-grown ones. These microstructural changes are reflected on the thermoelectric properties which increase with the grain orientation and with the decrease on the secondary phases content mainly due to the electrical resistivity reduction. As a consequence, a raise on the power factor of about 2 and 5 times, compared with the classically sintered samples, were obtained for the as-grown and annealed samples, respectively. The maximum power factor obtained at 
$650^{\circ} \mathrm{C}$ in the annealed samples $\left(\sim 0.20 \mathrm{~mW} / \mathrm{K}^{2} \mathrm{~m}\right)$ is much higher than the obtained in sinter-forged textured materials at the same temperature.

Keywords: Grain growth, Sintering, Microstructure; Electrical resistivity; Thermopower

Corresponding author: Sh. Rasekh. shrasekh@unizar.es 


\section{Introduction}

Thermoelectric (TE) materials are attracting attention due to their ability to transform a temperature gradient into electrical power due to the well-known Seebeck effect. Their inherent characteristics have focused attention on these materials to be applied in practical applications as waste heat recovery devices [1] or solar thermoelectric generators [2]. Furthermore, they can also be used as heating/refrigeration devices [3]. The conversion efficiency of such materials is usually quantified by the dimensionless figure of merit $\mathrm{ZT}, \mathrm{TS}^{2} / \rho \kappa$ (in which the electrical part, $S^{2} / \rho$, is called power factor, $\left.P F\right)$, where $S$ is the Seebeck coefficient (or thermopower), $\rho$ the electrical resistivity, $\kappa$ the thermal conductivity, and $\mathrm{T}$ is the absolute temperature [4].

Nowadays, the commercial applications of thermoelectric devices are based on the use of alloys and/or intermetallic materials, such as $\mathrm{Bi}_{2} \mathrm{Te}_{3}$ or $\mathrm{CoSb}_{3}$, with high thermoelectric performances at relatively low temperatures. On the other hand, these materials posses some drawbacks, as they can be degraded at high temperatures under air and/or releasing toxic or heavy elements. These problems lead to the limitation of their working temperature limiting their effective performances, as can be deduced from the ZT expression. The temperature limitation was surpassed in 1997 by the discovery of high thermoelectric properties in the Na-Co-O system [5]. From the discovery of this thermoelectric oxide, much work has been performed on the CoO-based ceramics as promising thermoelectric materials for high temperature applications. The intense research work continues on these families, such as $\mathrm{Ca}_{3} \mathrm{Co}_{4} \mathrm{O}_{9}, \mathrm{LaCoO}_{3}, \mathrm{Bi}_{2} \mathrm{Sr}_{2} \mathrm{Co}_{2} \mathrm{O}_{9}$ and $\mathrm{Bi}_{2} \mathrm{Ca}_{2} \mathrm{Co}_{2} \mathrm{O}_{\mathrm{y}}$ with interesting thermoelectric properties and high working temperatures [6-9]. 
The crystal structure of these $\mathrm{CoO}$ families is composed of two different layers, with an alternate stacking of a common conductive $\mathrm{Cdl}_{2}$-type $\mathrm{CoO}_{2}$ layer with a two-dimensional triangular lattice and a block layer, composed of insulating rock-salt-type (RS) layers. The two sublattices (RS block and $\mathrm{Cdl}_{2}$-type $\mathrm{CoO}_{2}$ layer) possess common $a$ - and $c$-axis lattice parameters and $\beta$ angles but different $b$-axis length, causing a misfit along the $b$-direction [10]. It has been reported that the misfit factor and/or the charge of the RS block layer between the $\mathrm{CoO}_{2}$ ones govern the Seebeck coefficient values [11]. These crystallographic characteristics provide the basis for the modification of thermoelectric properties of a given material via chemical substitutions. The most common ones substitute an alkaline-earth by other cation, as $\mathrm{Ca}$ for $\mathrm{Sr}$ in $\mathrm{Bi}_{2} \mathrm{Sr}_{2} \mathrm{Co}_{1.8} \mathrm{O}_{x}$ [12] or $\mathrm{La}$ for $\mathrm{Ca}$ in $\mathrm{Ca}_{3} \mathrm{Co}_{4} \mathrm{O}_{9}$ [13], or $\mathrm{Co}$ by another transition metal, as $\mathrm{Cu}$ or $\mathrm{Cr}$ for $\mathrm{Co}$ in $\mathrm{Ca}_{3} \mathrm{Co}_{4} \mathrm{O}_{9}[14,15]$. Other usual substitutions are $\mathrm{Pb}$ for $\mathrm{Bi}$ in $\mathrm{Bi}_{2} \mathrm{Ca}_{2} \mathrm{Co}_{1.7} \mathrm{O}_{x}[16]$.

On the other hand, as layered cobaltites are materials with a strong crystallographical anisotropy, the alignment of plate-like grains by mechanical and/or chemical processes is necessary to attain macroscopic properties comparable to those obtained on single crystals. Some techniques have been shown to be adequate to obtain a good grain orientation in several oxide ceramic systems, as Template Grain Growth (TTG) [17], spark plasma sintering [18], hot pressing [19], laser floating zone melting (LFZ) [20], or electrically assisted laser floating zone (EALFZ) [21].

The aim of the present work is studying the modification of microstructure as well as the thermoelectric properties of $\mathrm{Bi}_{2} \mathrm{Sr}_{2} \mathrm{Co}_{1.8} \mathrm{O}_{x}$ when comparing the 
classically sintered materials with the laser floating zone textured and texturedannealed ones.

\section{Experimental}

The polycrystalline $\mathrm{Bi}_{2} \mathrm{Sr}_{2} \mathrm{Co}_{1.8} \mathrm{O}_{\mathrm{x}}$ ceramics used for this study have been prepared by the polymer solution method route [22]. To a suspensión of $\mathrm{Bi}\left(\mathrm{CH}_{3} \mathrm{CO}_{2}\right)_{2}\left(99.99+\%\right.$, Aldrich), $\mathrm{Sr}\left(\mathrm{CH}_{3} \mathrm{CO}_{2}\right) \cdot 2 \mathrm{H}_{2} \mathrm{O}$ (Reagent grade, Alfa Aesar), and $\mathrm{Co}\left(\mathrm{CH}_{3} \mathrm{CO}_{2}\right)_{2} \cdot 4 \mathrm{H}_{2} \mathrm{O}\left(98 \%\right.$, Panreac) powders in distilled $\mathrm{H}_{2} \mathrm{O}$, glacial acetic acid (ACS Reagent, Panreac) was added until a pink clear solution was formed. Polyethyleneimine (PEI) (50\% aqueous, Aldrich) was added to the above solution, which turned darker immediately due to the nitrogen-metal coordination. After partial evaporation ( 80 vol. \%) of water and acetic acid in a rotary evaporator, the concentrated solution, with a very high viscosity, was placed onto a hot plate until a very dark pink paste appeared. Further heating turned this paste to violet color, followed by a slow combustion with the release of brown fumes (nitrogen oxides). The resulting powder has then been thermally treated twice at 750 and $800{ }^{\circ} \mathrm{C}$ for about 12 hours under air, with an intermediate manual milling, in order to assure the complete decomposition of the carbonates. This thermal treatment is necessary and it has been designed specifically to avoid the presence of carbonates in the following steps [23]. These as-prepared powders were then used for the different processed samples:

a) Classical sintering process: The powders were uniaxially pressed at $400 \mathrm{MPa}$ for 1 minute in order to obtain green ceramic parallelepipeds ( $3 \mathrm{~mm} \times 3 \mathrm{~mm} \times$ $14 \mathrm{~mm}$ ), with an adequate size and shape for their thermoelectric 
characterization. These green bodies were subsequently sintered in the optimal conditions for this system, consisting in one step heating at $810^{\circ} \mathrm{C}$ for $24 \mathrm{~h}$ with a final furnace cooling [8].

b) Texturing process: The resulting powders were then cold isostatically pressed into latex tubes at $\sim 200 \mathrm{MPa}$ for around 2 minutes to obtain green ceramic cylinders which were subsequently used as feed in a LFZ device equipped with a continuous power Nd:YAG laser $(\lambda=1.06 \mu \mathrm{m})$. The processing of the different samples has been performed in the same conditions; they were directionally grown downwards from the melt at $30 \mathrm{~mm} / \mathrm{h}$ with a seed rotation of $3 \mathrm{rpm}$. Moreover, in order to assure compositional homogeneity of the molten zone, an opposite feed rotation of $15 \mathrm{rpm}$ has also been performed. Finally, after the texturing process, long (more than $15 \mathrm{~cm}$ ) and geometrically homogeneous ( $\sim 2 \mathrm{~mm}$ diameter) textured cylindrical rods have been produced as reported in previous works [24]. These bars were cut into pieces with the adequate dimensions for the thermoelectric measurements ( $15 \mathrm{~mm}$ long). c) Texturing-annealing process: Part of the samples obtained in the texturing process were subjected, after cutting, to a thermal treatment consisting in one step heating at $810^{\circ} \mathrm{C}$ for $24 \mathrm{~h}$ with a final furnace cooling to reduce the amount of secondary phases, as reported in previous works [25].

The identification of the main phases in all the samples was carried out using powder XRD in a Rigaku D/max-B X-ray powder diffractometer (CuKa radiation), between 10 and 70 degrees. Microstructure evolution has been observed using a scanning electron microscope (JEOL 6000) equipped with an energy dispersive X-ray spectroscopy (EDS) device, used to determine the elemental composition of the different phases. Polished sections of all samples 
have been observed to analyze the microstructural evolution with the different treatments. Electrical resistivity and Seebeck coefficient were simultaneously determined by the standard dc four-probe technique in a LSR3 measurement system (Linseis $\mathrm{GmbH}$ ), in the steady state mode, at temperatures ranging from 50 to $650^{\circ} \mathrm{C}$. With the electrical resistivity and Seebeck coefficient data, the power factor $\left(\mathrm{PF}=\mathrm{S}^{2} / \rho\right)$ has been calculated in order to determine the samples performances.

\section{Results and discussion}

Powder XRD patterns for all the $\mathrm{Bi}_{2} \mathrm{Sr}_{2} \mathrm{Co}_{1.8} \mathrm{O}_{x}$ samples (from 10 to 40 degrees, for clarity), are displayed in Fig. 1. From these data, it is clear that the most intense peaks correspond to the $\mathrm{Bi}_{2} \mathrm{Sr}_{2} \mathrm{Co}_{1.8} \mathrm{O}_{x}$ phase (indicated by their diffraction planes in Fig. 1a, in agreement with previously published data [26]. On the other hand, peaks marked with $\bullet$ and $\bullet$ in Fig. 1a correspond to the $\mathrm{Bi}_{0.75} \mathrm{Sr}_{0.25} \mathrm{O}_{y}$ [27] and $\mathrm{Sr}_{6} \mathrm{Co}_{5} \mathrm{O}_{14.3}$ [28] secondary phases, respectively. When observing carefully the patterns displayed in the figure, it can be clearly seen that the relative intensity of reflections attributed to the secondary phases decrease from the samples prepared by the classical solid state method (Fig. 1a) to the textured ones (Fig. 1b). Moreover, the annealing treatment still decreased the amount of secondary phases, as can be observed by the nearly total disappearance of the peaks corresponding to the secondary phases (see

Fig. 1c). This result clearly indicates that the temperature and time are adequate to produce nearly pure phase textured thermoelectric materials. On the other hand, it can also be observed the disappearance of some peaks belonging to the $\mathrm{Bi}_{2} \mathrm{Sr}_{2} \mathrm{Co}_{1.8} \mathrm{O}_{\mathrm{x}}$ phase with the annealing process. As it is well 
known, the thermoelectric grains mostly grow along the ab planes, as reported in previous works [29], producing plate-like grains. As a consequence, the preparation of powdered samples can induce different preferential grain orientations in the powders. This is a typical effect associated with samples composed of very anisotropic grains (as plate-like ones).

Representative SEM micrographs of longitudinal sintered and as-grown fractured samples are shown in Fig. 2. In these micrographs it can be easily seen the microstructural evolution with the different processing processes. Classical sintered samples (Fig. 2a) show small (5-10 $\mu \mathrm{m}$ in the ab plane) randomly oriented plate-like grains while the as-grown ones possess very large (more than $100 \mu \mathrm{m}$ in the ab plane) well aligned grains stacked long their ab planes (Fig. 2b). In any case, it is difficult to establish the grains dimensions in the $c$ axis, even when observing at higher magnification (see Fig. 2c) where it can be observed that all the grains are formed by very thin plate-like grains perfectly stacked along their ab planes. Due to the difficulty inherent to the determination of thickness of each individual grain by SEM observations, an estimation of their thickness has been performed from the XRD results applying Scherrer's formula using the (006) and (0010) diffraction peaks. The obtained mean value for the grain thickness is about $35 \mathrm{~nm}$ in all cases, which confirms that the crystal preferential growth is produced along the ab plane.

Representative SEM micrographs of longitudinal sintered and as-grown polished samples are shown in Fig. 3. In these images it is clear that the grain sizes of the sintered samples (Fig. 3a) are much lower than for the textured ones (Fig. 3b and c). Moreover, it can be observed that grey contrast (\#1), associated by EDS to the thermoelectric $\mathrm{Bi}_{2} \mathrm{Sr}_{2} \mathrm{Co}_{1.8} \mathrm{O}_{x}$ phase, is the major one 
in all cases. The other contrasts correspond to secondary phases and they are dark grey (\#2) with $\mathrm{Sr}_{3} \mathrm{Co}_{4} \mathrm{O}_{x}$ composition, light grey (\#3) with different composition in the sintered $\left(\mathrm{Bi}_{0.75} \mathrm{Sr}_{0.22} \mathrm{O}_{y}\right)$ or textured samples $\left(\mathrm{Bi}_{2} \mathrm{SrO}_{\mathrm{x}}\right)$. Finally, black contrast (\#4) has been identified as CoO.

Other feature that can be observed in the micrographs is the relatively high porosity in the sintered specimens while nearly no porosity can be observed in the textured and textured annealed samples. Moreover, in the textured annealed samples thermoelectric phase amount is higher than in the textured ones without losing their grain orientation.

The effect of the different processing methods on the thermoelectric properties of these ceramics has been determined by electrical resistivity and Seebeck coefficient measurements. The temperature dependence of the electrical resistivity, as a function of the preparation method, has been measured and represented in Fig. 4. As it can be easily observed in the plot, two different behaviours can be observed, one for the classically sintered and as-grown samples and another one for the textured and annealed ones. The first ones show a marked semiconducting-like behaviour $(d \rho / d T<0)$ in all the measured temperature range. In the case of the textured and annealed samples, they show a clear metallic-like behaviour $(\mathrm{d} \rho / \mathrm{dT}>0)$ in all the measured temperature range, with lower resistivity values than the obtained in the other samples. The evolution of resistivity with the different processing can be explained taking into account the microstructural features discussed previously. The behaviour of the classically sintered materials is the typical observed in this kind of materials when they are formed by randomly oriented grains and possess an appreciable amount of isolating secondary phases. The as-grown samples show a good 
grain orientation and lower number of grain boundaries due to their larger size. As a consequence, and in spite of an important raise on the secondary phases content, the resistivity values decrease, indicating that grain orientation and lower amount of grain boundaries have higher influence on the electrical resistivity than the amount of secondary phases. Moreover, when the as-grown samples are annealed, further decrease on the electrical resistivity is produced by the reduction on the secondary phases content. In any case, this decrease is lower than the produced by the texturing process, confirming that the secondary phases affect, in a lower extent than the grain orientation and size, the electrical resistivity values. The lowest resistivity values at $650^{\circ} \mathrm{C}$ measured in the textured and annealed samples $(\sim 20 \mathrm{~m} \Omega . \mathrm{cm})$ are close to the values obtained in sintered materials under oxygen ( $15 \mathrm{~m} \Omega . \mathrm{cm})[17]$ or single crystals $(\sim 18$ $\mathrm{m} \Omega . \mathrm{cm}$ at room temperature) [30]. Moreover, they are much lower than the measured on sinter-forged materials $(\sim 40 \mathrm{~m} \Omega . \mathrm{cm})$ [31].

Fig. 5 displays the Seebeck coefficient variation with temperature, as a function of the processing method. It is evident that the sign of the thermopower is positive for the entire measured temperature range for all the samples which confirms a conduction mechanism mainly governed by holes. In this case, the sintered and the textured annealed samples possess similar Seebeck coefficient and behaviour. On the other hand, the as-grown ones show a very different behaviour and lower Seebeck values at high temperatures. The difference between both groups of samples can be explained by the higher amount of secondary phases found in the as-grown ones which reduce the thermoelectric phase content. On the other hand, the sintered and textured annealed samples possess higher amount of $\mathrm{Bi}_{2} \mathrm{Sr}_{2} \mathrm{Co}_{1.8} \mathrm{O}_{\mathrm{x}}$ thermoelectric 
phase. The highest Seebeck coefficient has been obtained for the sintered samples at $650^{\circ} \mathrm{C}(\sim 205 \mu \mathrm{V} / \mathrm{K})$, very close to the obtained in textured annealed ones $(\sim 200 \mu \mathrm{V} / \mathrm{K})$ and higher than the obtained in sinter-forged materials $(\sim$ $150 \mu \mathrm{V} / \mathrm{K})$ [31]. Moreover, the room temperature values are much higher than the obtained in sintered materials under oxygen at the same temperature $(\sim 40$ $\mu \mathrm{V} / \mathrm{K})[17]$.

In order to evaluate the thermoelectric performances of these materials, PF has been calculated from the resistivity and Seebeck coefficient values and plotted in Fig. 6. When considering PF values at about $50{ }^{\circ} \mathrm{C}$ ( room temperature), it can be clearly seen that sintered samples show the lowest values (around 0.02 $\left.\mathrm{mW} / \mathrm{K}^{2} \mathrm{~m}\right)$. The texturing process promotes a very important increase at this temperature, reaching around $0.05 \mathrm{~mW} / \mathrm{K}^{2} \mathrm{~m}$, while the annealing produces further increase until about $0.10 \mathrm{~mW} / \mathrm{K}^{2} \mathrm{~m}$. In any case, these values are much higher than the obtained in sintered materials under oxygen at the same temperature $\left(\sim 0.01 \mathrm{~mW} / \mathrm{K}^{2} \mathrm{~m}\right)$ [17]. Moreover, the maximum $\mathrm{PF}$ value at $650^{\circ} \mathrm{C}$ $\left(\sim 0.20 \mathrm{~mW} / \mathrm{K}^{2} \mathrm{~m}\right)$ for the textured annealed samples is around the best obtained in sinter-forged materials at the same temperature $\left(\sim 0.06 \mathrm{~mW} / \mathrm{K}^{2} \mathrm{~m}\right)[31]$.

\section{Conclusions}

The effect of the processing method on the microstructure and thermoelectric properties of intrinsically nanostructured $\mathrm{Bi}_{2} \mathrm{Ca}_{2} \mathrm{Co}_{1.7} \mathrm{O}_{x}$ ceramic materials has been studied. The microstructure has shown that all samples possess $\mathrm{Bi}_{2} \mathrm{Ca}_{2} \mathrm{Co}_{1.7} \mathrm{O}_{\mathrm{x}}$ thermoelectric phase as the major one. Moreover, the thermoelectric grains are formed by the close stacking of nanometric grains (around $35 \mathrm{~nm}$ ) in the c-direction. Sintered samples showed randomly oriented 
grains while the textured ones have very well oriented grains with their c-axis nearly perpendicular to the growth direction. The observed microstructures have an important impact on the thermoelectric properties, which increase from the sintered samples to the as-grown and the annealed ones. This effect is mainly produced by the decrease on the electrical resistivity of these samples.

Maximum PF values at $650{ }^{\circ} \mathrm{C}$ (about $0.20 \mathrm{~mW} / \mathrm{K}^{2} \mathrm{~m}$ ) are much higher than the best ones reported in the literature for hot-forged textured materials. All these results show that $\mathrm{Bi}_{2} \mathrm{Sr}_{2} \mathrm{Co}_{1.8} \mathrm{O}_{x}$ directionally grown and annealed ceramics are promising materials for practical applications.

\section{Acknowledgements}

The authors wish to thank the MINECO-FEDER (Project MAT2013--46505-C31-R) and the Gobierno de Aragón (Research Groups T12 and T87) for financial support. Sh. Rasekh acknowledges a JAE-Predoc 2010 grant from CSIC. The technical contributions of C. Estepa and C. Gallego are also acknowledged. 


\section{References}

[1] Mahan G, Sales B, Sharp J. Thermoelectric materials: New approaches to an old problem. Phys Today 1997;50:42-7

[2] Naito H, Kohsaka Y, Cooke D, Arashi H. Development of a solar receiver for a high-efficiency thermoionic/thermoelectric conversion system. Sol Energy 1996;58:191-5

[3] Kim CM, Hwang YJ, Ryu YH. US Patent US6393842. May, 2002

[4] Rowe DM. Thermoelectrics handbook: macro to nano. 1st ed. Boca Raton, FL: CRC Press; 2006

[5] Terasaki I, Sasago Y, Uchinokura K. Large thermoelectric power in $\mathrm{NaCo}_{2} \mathrm{O}_{4}$ single crystals. Phys Rev B 1997;56:12685-7

[6] Sotelo A, Constantinescu G, Rasekh Sh, Torres MA, Diez JC, Madre MA. Improvement of thermoelectric properties of $\mathrm{Ca}_{3} \mathrm{Co}_{4} \mathrm{O}_{9}$ using soft chemistry synthetic methods. J Eur Ceram Soc 2012;32:2415-22

[7] Li F, Li JF, Li JH, Yao FZ. The effect of Cu substitution on microstructure and thermoelectric properties of $\mathrm{LaCoO}_{3}$ ceramics. Phys Chem Chem Phys $2012 ; 14: 12213-20$

[8] Torres MA, Sotelo A, Rasekh Sh, Serrano I, Constantinescu G, Madre MA, Diez JC. Improvement of thermoelectric properties of $\mathrm{Bi}_{2} \mathrm{Sr}_{2} \mathrm{Co}_{1.8} \mathrm{O}_{\mathrm{x}}$ through solution synthetic methods. Bol Soc Esp Ceram V 2012;51:1-6 [9] Sotelo A, Rasekh Sh, Madre MA, Guilmeau E, Marinel S, Diez JC. Solutionbased synthesis routes to thermoelectric $\mathrm{Bi}_{2} \mathrm{Ca}_{2} \mathrm{Co}_{1.7} \mathrm{O}_{\mathrm{x}}$. J Eur Ceram Soc $2011 ; 31: 1763-9$

[10] Miyazaki Y. Crystal structure and thermoelectric properties of the misfitlayered cobalt oxides. Solid State Ionics 2004;172:463-7 
[11] Maignan A, Pelloquin D, Hebert S, Klein Y, Hervieu M. Thermoelectric power in misfit cobaltites ceramics: Optimization by chemical substitutions. Bol Soc Esp Ceram V 2006;45:122-5

[12] Sun N, Dong ST, Zhang BB, Chen YB, Zhou J, Zhang ST, Gu ZB, Yao SH, Chen YF. Intrinsically modified thermoelectric performance of alkaline-earth isovalently substituted $\left[\mathrm{Bi}_{2} \mathrm{AE}_{2} \mathrm{O}_{4}\right]\left[\mathrm{CoO}_{2}\right]_{y}$ single crystals. J Appl Phys 2013;114:043705

[13] Butt S, Liu Y-C, Lan J-L, Shehzad K, Zhan B, Lin Y, Nan C-W. Hightemperature thermoelectric properties of $\mathrm{La}$ and Fe co-doped $\mathrm{Ca}-\mathrm{Co}-\mathrm{O}$ misfitlayered cobaltites consolidated by spark plasma sintering. J Alloys Compds $2014 ; 588: 277-83$

[14] Diez JC, Torres MA, Rasekh Sh, Constantinescu G, Madre MA, Sotelo A. Enhancement of $\mathrm{Ca}_{3} \mathrm{Co}_{4} \mathrm{O}_{9}$ thermoelectric properties by $\mathrm{Cr}$ for Co substitution. Ceram Int 2013;39:6051-6

[15] Prasoetsopha N, Pinitsoontorn S, Kamwanna T, Amornkitbamrung V, Kurosaki K, Ohishi Y, Muta H, Yamanaka S. The effect of $\mathrm{Cr}$ substitution on the structure and properties of misfit-layered $\mathrm{Ca}_{3} \mathrm{Co}_{4-x} \mathrm{Cr}_{x} \mathrm{O}_{9+\delta}$ thermoelectric oxides. J Alloys Compnds 2014;588:199-205

[16] Madre MA, Torres MA, Rasekh Sh, Diez JC, Sotelo A. Improvement of thermoelectric performances of $\mathrm{Bi}_{2} \mathrm{Sr}_{2} \mathrm{Co}_{1.8} \mathrm{O}_{x}$ textured materials by $\mathrm{Pb}$ addition using a polymer solution method. Mater Lett 2012;75:5-7

[17] Itahara H, Xia C, Sugiyama J, Tani T. Fabrication of textured thermoelectric layered cobaltites with various rock salt-type layers by using $\beta-\mathrm{Co}(\mathrm{OH})_{2}$ platelets as reactive templates. J Mater Chem 2004;14:61-6 
[18] Wu NY, Holgate TC, Nong NV, Pryds N, Linderoth S. High temperature thermoelectric properties of $\mathrm{Ca}_{3} \mathrm{Co}_{4} \mathrm{O}_{9+\delta}$ by auto-combustion synthesis and spark plasma sintering. J Eur Ceram Soc 2014;34:925-31

[19] Wang H, Sun X, Yan X, Huo D, Li X, Li J-G, Ding X. Fabrication and thermoelectric properties of highly textured $\mathrm{Ca}_{9} \mathrm{Co}_{12} \mathrm{O}_{28}$ ceramic. J Alloys Compds 2014;582:294-8

[20] Sotelo A, Guilmeau E, Madre MA, Marinel S, Lemmonier S, Diez JC. $\mathrm{Bi}_{2} \mathrm{Ca}_{2} \mathrm{Co}_{1.7} \mathrm{O}_{\mathrm{x}}$ thermoelectric ceramics textured by laser floating zone method. Bol Soc Esp Ceram V 2008;47:225-8

[21] Ferreira NM, Rasekh Sh, Costa FM, Madre MA, Sotelo A, Diez JC, Torres MA. New method to improve the grain alignment and performance of thermoelectric ceramics. Mater Lett 2012;83:144-7

[22] Madre MA, Rasekh Sh, Diez JC, Sotelo A. New solution method to produce high performance thermoelectric ceramics: A case study of Bi-Sr-Co-O. Mater Lett 2010;64:2566-8

[23] Diez JC, Guilmeau E, Madre MA, Marinel S, Lemonnier S, Sotelo A. Improvement of $\mathrm{Bi}_{2} \mathrm{Sr}_{2} \mathrm{Co}_{1.8} \mathrm{O}_{x}$ thermoelectric properties by laser floating zone texturing. Solid State Ionics 2009;180:827-30

[24] Sotelo A, Guilmeau E, Rasekh Sh, Madre MA, Marinel S, Diez JC.

Enhancement of the thermoelectric properties of directionally grown $\mathrm{Bi}-\mathrm{Ca}-\mathrm{Co}-\mathrm{O}$ through $\mathrm{Pb}$ for Bi substitution. J Eur Ceram Soc 2010;30:1815-20

[25] Diez JC, Rasekh Sh, Constantinescu G, Madre MA, Torres MA, Sotelo A. Effect of annealing on the thermoelectric properties of directionally grown $\mathrm{Bi}_{2} \mathrm{Sr}_{2} \mathrm{Co}_{1.8} \mathrm{O}_{x}$ ceramics. Ceram Int 2012;38:5419-24 
[26] Sotelo A, Torres MA, Constantinescu G, Rasekh Sh, Diez JC, Madre MA. Effect of Ag addition on the mechanical and thermoelectric performances of annealed $\mathrm{Bi}_{2} \mathrm{Sr}_{2} \mathrm{Co}_{1.8} \mathrm{O}_{\mathrm{x}}$ textured ceramics. J Eur Ceram Soc 2012;32:3745-51 [27] Mercurio D, Champarnaud-Mesjard JC, Frit B, Conflant P, Boivin JC, Vogt T. Thermal evolution of the crystal-structure of the rhombohedral $\mathrm{Bi}_{0.75} \mathrm{Sr}_{0.25} \mathrm{O}_{1.375}$ phase-a single-crystal neutron-diffraction study. J Solid State Chem 1994;112:1-8 [28] Iwasaki K, Yamane H, Murase T, Yoshino M, Ito T, Nagasaki T, Arita Y, Matsui T. Crystal structure of an oxygen deficient strontium cobaltate, $\mathrm{Sr}_{6} \mathrm{Co}_{5} \mathrm{O}_{14.3 .}$ J Ceram Soc Jpn 2009;117:89-3 [29] Diez JC, Rasekh Sh, Madre MA, Guilmeau E, Marinel S, Sotelo A. Improved thermoelectric properties of $\mathrm{Bi}-\mathrm{M}-\mathrm{Co}-\mathrm{O}(\mathrm{M}=\mathrm{Sr}, \mathrm{Ca})$ misfit compounds by laser directional solidification. J Electron Mater 2010;39:1601-5 [30] Itoh T, Terasaki I. Thermoelectric properties of $\mathrm{Bi}_{2.3-x} \mathrm{~Pb}_{x} \mathrm{Sr}_{2.6} \mathrm{Co}_{2} \mathrm{O}_{y}$ single crystals. Jpn J Appl Phys 2000;39:6658-60

[31] Shin W, Murayama N. Thermoelectric properties of (Bi,Pb)-Sr-Co-O oxide. J Mater Res 2000;15:382-6 


\section{Figure captions}

Figure 1. XRD plots of all the samples: a) classically sintered at $810^{\circ} \mathrm{C}$ for 24 h; b) as-grown textured sample; and c) textured and annealed at $810^{\circ} \mathrm{C}$ for 24 h. Crystallographic planes have been indicated on the peaks corresponding to the $\mathrm{Bi}_{2} \mathrm{Sr}_{2} \mathrm{Co}_{1.8} \mathrm{O}_{\mathrm{y}}$ thermoelectric phase. $\bullet$ and $\bullet$ indicate the $\mathrm{Bi}_{0.75} \mathrm{Sr}_{0.25} \mathrm{O}_{\mathrm{y}}$, and $\mathrm{Sr}_{6} \mathrm{Co}_{5} \mathrm{O}_{14.3}$ secondary phases, respectively.

Figure 2. Representative SEM micrographs of longitudinal fractured samples a) sintered at $810^{\circ} \mathrm{C}$ for $24 \mathrm{~h} ; \mathrm{b}$ ) textured by the LFZ technique; and c) high magnification of the textured sample.

Figure 3. Representative SEM micrographs of longitudinal polished samples a) sintered at $810^{\circ} \mathrm{C}$ for $24 \mathrm{~h}$; b) textured by the LFZ technique; and c) textured by LFZ and annealed at $810^{\circ} \mathrm{C}$ for $24 \mathrm{~h}$. \#1 (grey contrast) $\mathrm{Bi}_{2} \mathrm{Sr}_{2} \mathrm{Co}_{1.8} \mathrm{O}_{\mathrm{y}}$ thermoelectric phase; \#2 (dark grey) $\mathrm{Sr}_{3} \mathrm{Co}_{4} \mathrm{O}_{x}$; \#3 (light grey) $\mathrm{Bi}_{0.75} \mathrm{Sr}_{0.22} \mathrm{O}_{y}$ (in a) or $\mathrm{Bi}_{2} \mathrm{SrO}_{x}$ (in b and c); and \#4 (black) CoO.

Figure 4. Temperature dependence of the electrical resistivity of $\mathrm{Bi}_{2} \mathrm{Sr}_{2} \mathrm{Co}_{1.8} \mathrm{O}_{x}$ samples, as a function of the processing technique. $\bullet$ sintered at $810^{\circ} \mathrm{C}$ for 24 $\mathrm{h} ;$ textured by the LFZ technique; and $\boldsymbol{\nabla}$ textured and annealed at $810^{\circ} \mathrm{C}$ for $24 \mathrm{~h}$.

Figure 5. Temperature dependence of the Seebeck coefficient of $\mathrm{Bi}_{2} \mathrm{Sr}_{2} \mathrm{Co}_{1.8} \mathrm{O}_{x}$ samples, as a function of the processing technique. $\bullet$ sintered at $810^{\circ} \mathrm{C}$ for 24 
h; textured by the LFZ technique; and $\boldsymbol{\nabla}$ textured and annealed at $810^{\circ} \mathrm{C}$ for $24 \mathrm{~h}$.

Figure 6. Temperature dependence of the power factor of $\mathrm{Bi}_{2} \mathrm{Sr}_{2} \mathrm{Co}_{1.8} \mathrm{O}_{x}$ samples, as a function of the processing technique. $\bullet$ sintered at $810^{\circ} \mathrm{C}$ for 24 $\mathrm{h} ;$ textured by the LFZ technique; and $\boldsymbol{\nabla}$ textured and annealed at $810^{\circ} \mathrm{C}$ for $24 \mathrm{~h}$. 
Figure 1

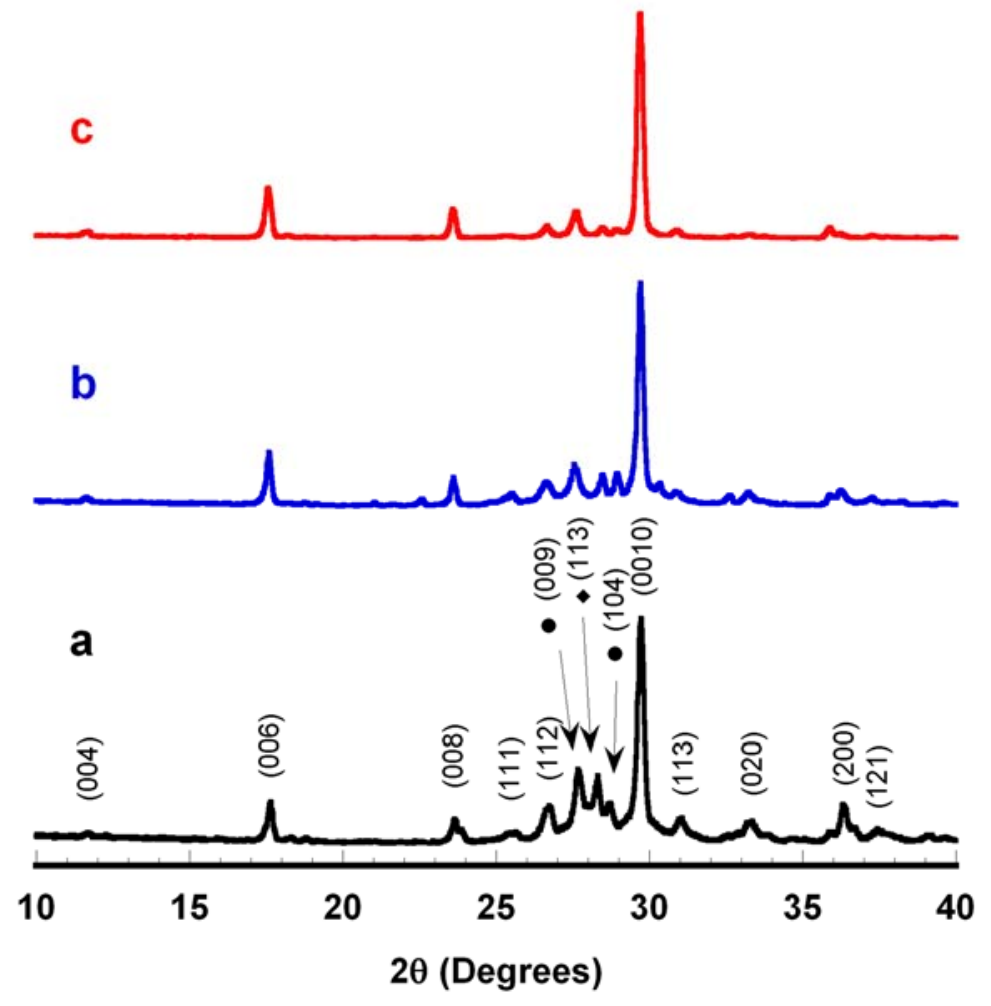


Figure 2
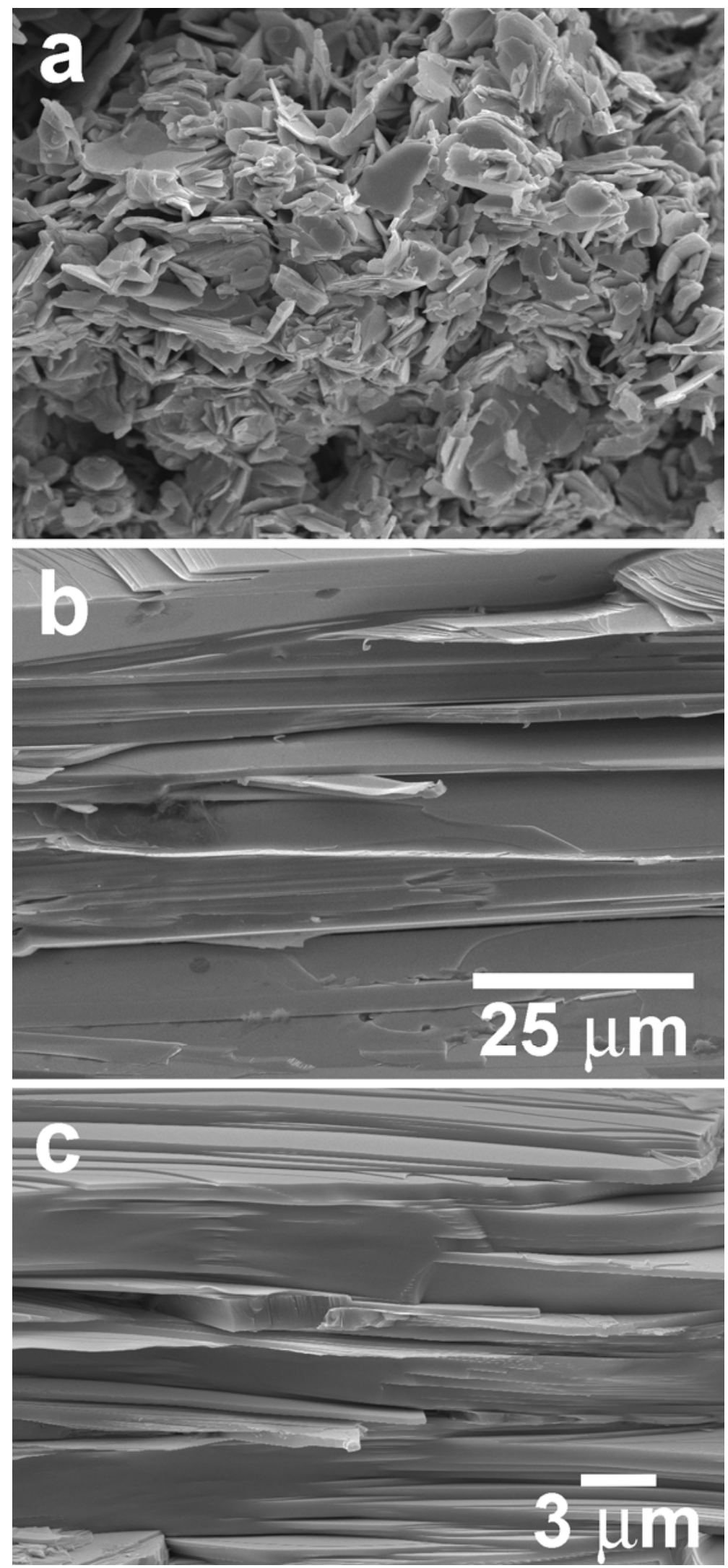
Figure 3
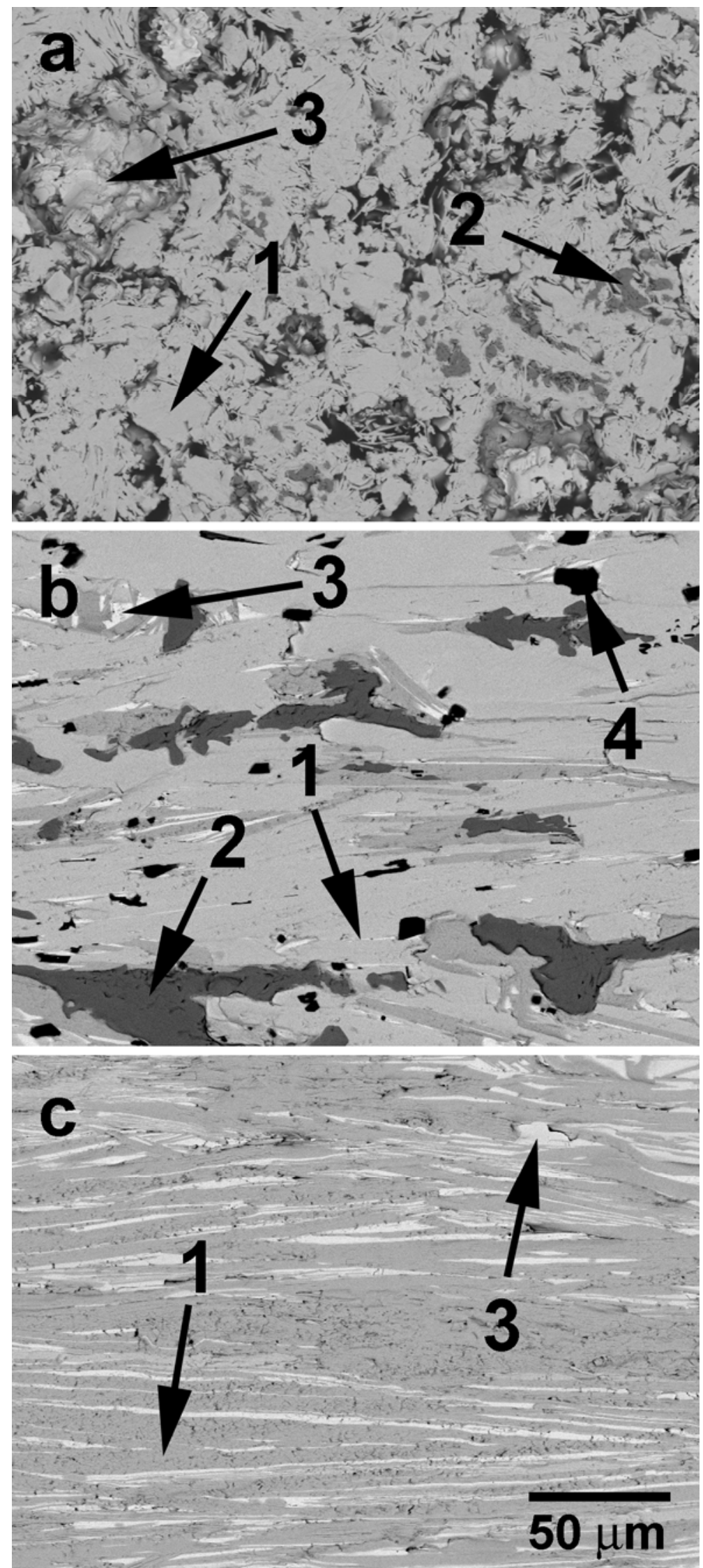
Figure 4

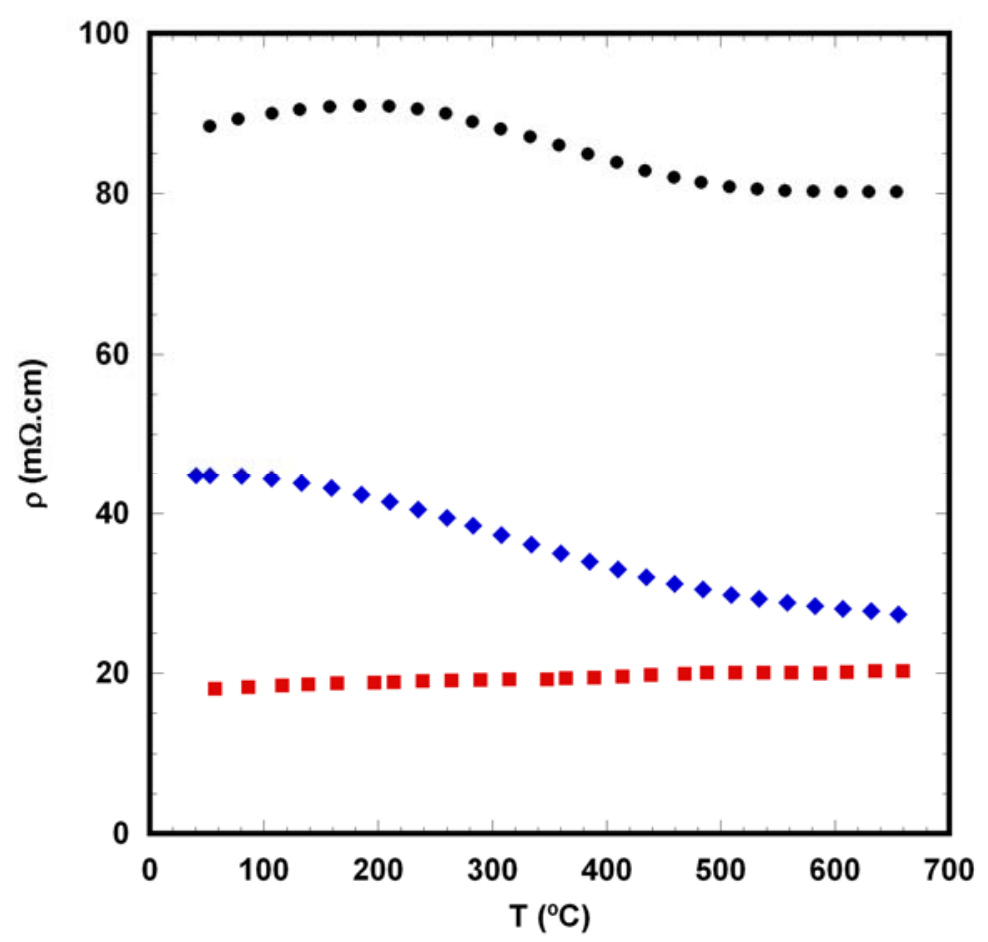


Figure 5

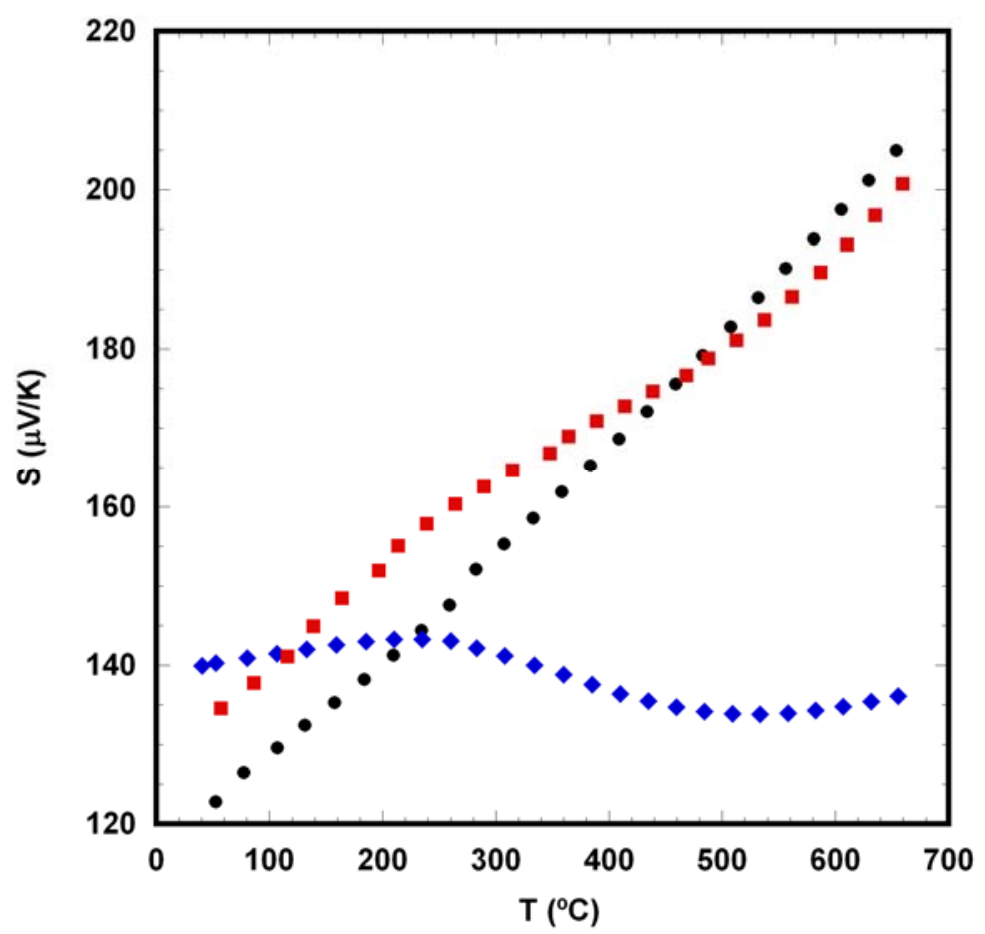


Figure 6

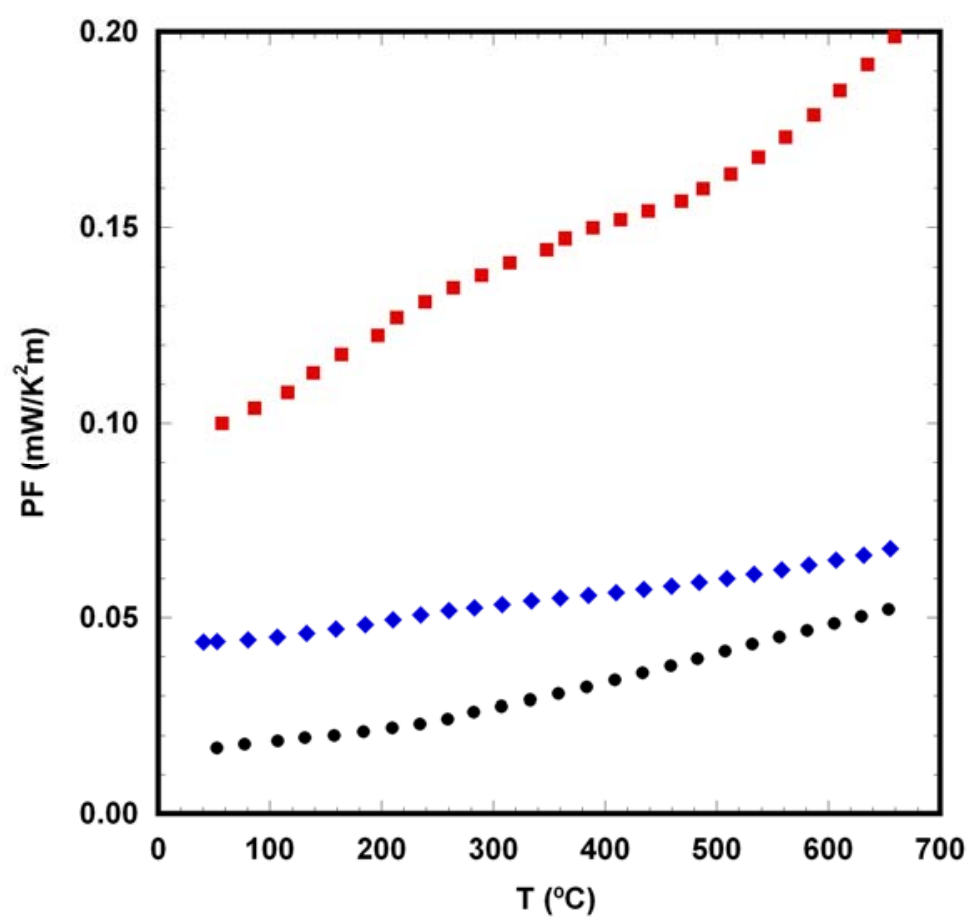

